\title{
Implementation of Passive Filters for Harmonics Reduction
}

\author{
Mandeep Singh $^{1}$ and Sheila Mahapatra ${ }^{2}$ \\ ${ }^{1,2}$ Department of EECE, ITM University, Gurgaon \\ ${ }^{1}$ mandeepsingh@itmindia.edu, ${ }^{2}$ sheila@itmindia.edu
}

\begin{abstract}
In recent years there has been widespread use of power electronics devices and nonlinear elements in rectification and switchgear applied to various areas of power system. Power systems contain levels of harmonics which can no longer be ignored by engineers, planners, energy conservationists and economists due to the presence of non-linear loads. A simulated case study of distributed system in IEEE 519 is being used here for harmonic reduction. From the simulated case study, the network was investigated using MiPower software package. The results were compared with IEEE standards 519 and it was found that MiPower software is the preferred package for power system harmonic analysis. The harmonic reduction solution chosen was to design a passive filter to decrease the distortion by shifting the resonance point of the network. This paper includes the method to design the passive filter and its impact on efficiency and energy usage.
\end{abstract}

Keywords: Harmonic analysis, Mi Power software, Total harmonic Distortion (THD), passive filters, Current distortion limits

\section{Introduction}

There is a great emphasis about power quality and in particular the issue of harmonic distortion primarily due to the incorporation of more non-linear loads in a typical industrial plant [1]. Further, power electronic based devices are widely being used for inversion, rectification and other applications. Though these devices are more effective they generate and inject harmonics into the power system. Traditionally, efficiency investigations in power systems consider only distortion-free waveforms, that is, the voltage and current waveforms are assumed to be sinusoidal. A harmonic is a sinusoidal component of a periodic wave having a frequency that is an integral multiple of the fundamental frequency. The main sources of harmonics in power systems has been the static power converter used as rectifiers, adjustable speed drives, switched-mode supplies, frequency changers for induction heating. Since nonlinear loads represent an everincreasing percentage of the total load of an industrial or commercial power system, harmonic studies have become an important part of overall system design and operation. Fortunately, the available software for harmonic analysis has also grown. Guidelines for the acceptance of harmonic distortion are well-defined in IEEE Standard 519-1992. By modeling power system impedances as a function of frequency, a study can be made to determine the effect of the harmonic contributions from nonlinear loads on the voltages and currents in the power system. The current paper is structured as follows: In Section II, the purpose of harmonic study and its effect are discussed. The test system investigated for harmonic analysis and methods used for harmonic reduction are given in Section III. The implementation of passive filters for harmonic content reduction is given in Section IV. The simulation results are given in Section V \& conclusion in Section VI. 


\section{Harmonic Sources and its Effect}

An adjustable speed drives (ASD) consists of two main components - the drive and the motor it controls. Each component has an efficiency rating. When an ASD is connected to a power system it absorbs power $(P 1)$ at fundamental frequency $(f 1)$ from the network source while at the same time injecting harmonics into the system producing powers at $h>1$ in the network components. A further concern is that power networks contain capacitor banks and have the potential to cause harmonic resonance. The generated harmonic frequencies are dependent upon the type of nonlinear load which generally produce odd harmonics. Industrial harmonic studies are usually represented on a singlephase basis, i.e., based on the assumption that the system is balanced and positive sequence analysis applies. Harmonic study is done in Compliance with IEEE Std 5191992, which defines the current distortion limits and Voltage distortion limits for the system design which should be met at the point of common coupling (PCC) with the utility [5]. This holds relevance in plant expansion where significant nonlinear loads are added, power factor compensation is implemented to meet the reactive power demands and harmonic performance limits. The ill-effects of harmonics are increased if resonance occurs where the harmonic frequency produced by a non-linear load closely coincides with a power system natural frequency. Parallel resonance occurs when the natural frequency of the parallel combination of capacitor banks and the system inductance coincides near a harmonic frequency and it can lead to undesirable over voltages.

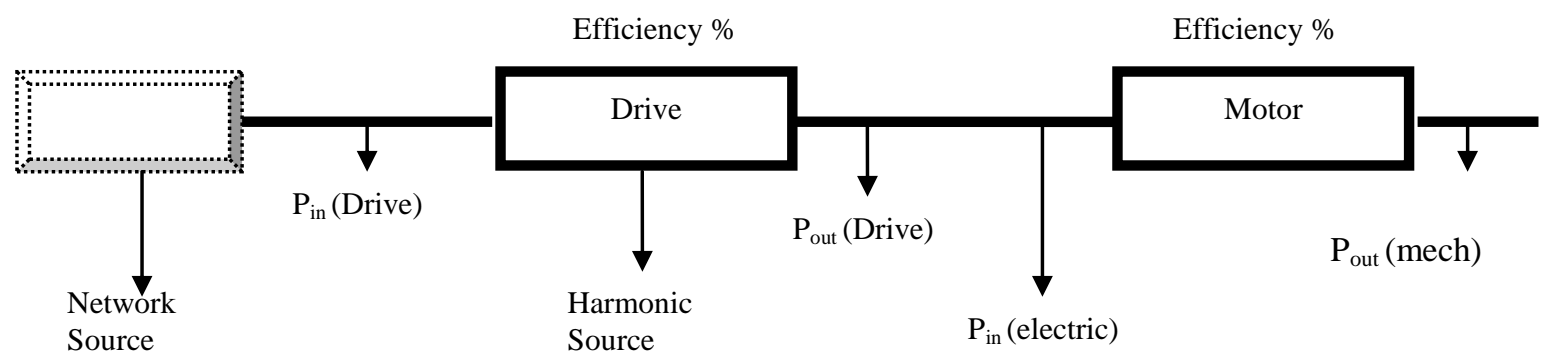

Figure 1. One Individual ASD

Some of the common adverse consequences of harmonics on power system performance are increased losses within the equipment and associated cables and lines, pulsating and reduced torque in rotating equipment, premature aging due to increased stress in the equipment insulation, increased audible noise from rotating and static equipment, substantial amplification of currents and voltages due to resonances, and communication interference due to inductive coupling between power and communication circuits. In a three-phase system the characteristic harmonic currents are

$i_{R}=I_{1 m} \cos (\omega t)-I_{5 m} \cos (5 \omega t)+I_{7 m} \cos (7 \omega t)-I_{11 m} \cos (11 \omega t)$

$i_{Y}=I_{1 m} \cos \left(\omega t-120^{\circ}\right)-I_{5 m} \cos \left(5 \omega t-240^{\circ}\right)+I_{7 m} \cos \left(7 \omega t-120^{\circ}\right)-I_{11 m} \cos \left(11 \omega t-240^{\circ}\right)$

$i_{B}=I_{1 m} \cos \left(\omega t+120^{\circ}\right)-I_{5 m} \cos \left(5 \omega t+240^{\circ}\right)+I_{7 m} \cos \left(7 \omega t+120^{\circ}\right)-I_{11 m} \cos \left(11 \omega t+240^{\circ}\right)$

The total harmonic distortion (THD) is a measure of the effective value of the harmonic components of a distorted waveform. It can be calculated for either voltage or current distortion as follows: 
$\% T H D=\frac{\sqrt{\sum_{h>1}^{h_{\max }} F_{h}^{2}}}{F_{1}} \times 100 \%$

$$
\% H D=\frac{F_{h}}{F_{1}} \times 100 \%
$$

Where $F_{h}$ is the Rms value of harmonic component $h$ of the quantity $F$ (voltage or current) and $F_{1}$ is the magnitude at $h=1$. The distortion level caused by individual harmonic components (voltage or current magnitudes) is expressed as a percentage of the fundamental component magnitude and used as a measure of observing which harmonic component contributes more to the total harmonic distortion. Therefore, equations above can be expressed in terms of voltage and current as follows

$\% V_{T H D}=\frac{\sqrt{\sum_{h=2} V_{h}^{2}}}{V_{1}} \times 100 \%$

$\% V_{H D}=\frac{V_{h}}{V_{1}} \times 100 \%$
$\% I_{T H D}=\frac{\sqrt{\sum_{h=2} I_{h}^{2}}}{I_{1}} \times 100 \%$

\section{Power System Model under Study}

The test system was designed using Mi Power Software taking IEEE 519-1992 into consideration [5]. The 8 bus system consist of three series capacitor for reducing fault level, four transformers each rated to $10 \mathrm{MVA}$, four current sources to inject current harmonics into the system, one grid having a fault level of 350 short circuit MVA rating. A basic load flow using Fast Decoupled method is done to get the actual current flowing through the load based upon which the harmonic currents are calculated. Various harmonic currents were injected into the system to get the outputs for current and voltage distortions and individual contributions from various harmonic loads. These distortions must be restricted to the values as provided in IEEE 519 standard either individually and as a whole particularly at PCC.

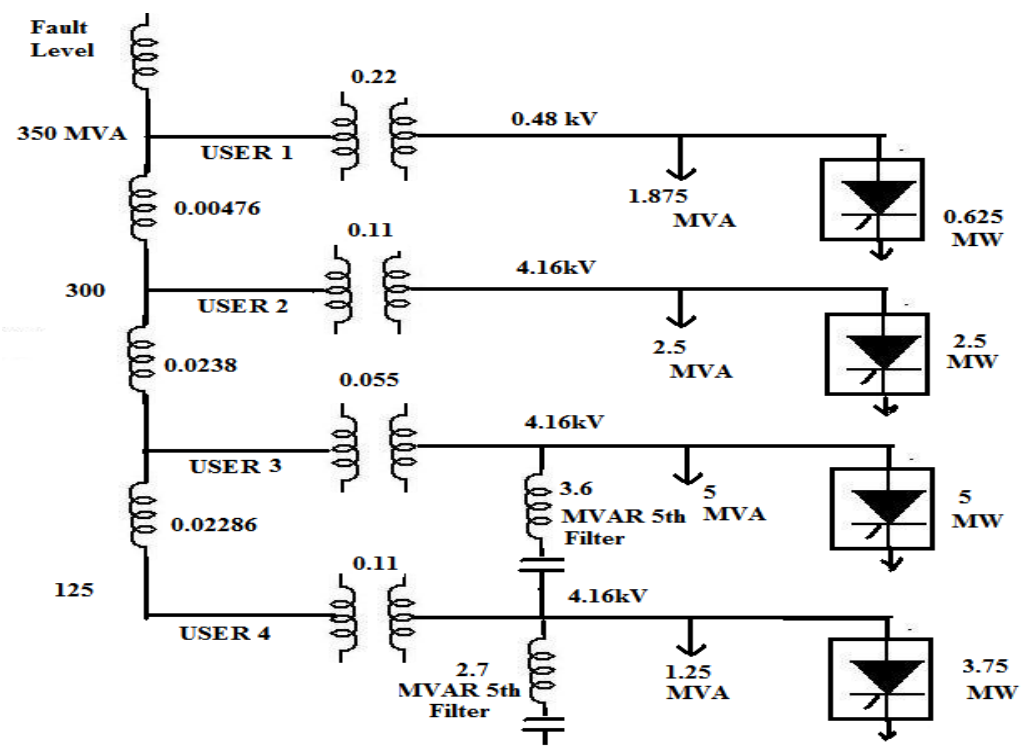

Figure 2. Single-Line Diagram of Distribution System Feeder Used in Calculation of Current and Voltage Distortion 
The limits for voltage distortion as given in IEEE 519 harmonic standards are provided in Table 1-2.

Table 1. Voltage Distortion Limits

\begin{tabular}{|c|c|c|}
\hline Bus Voltage at PCC & $\begin{array}{c}\text { Individual Voltage } \\
\text { Distortion }(\%)\end{array}$ & $\begin{array}{c}\text { Total Voltage Distortion } \\
\text { THD }(\%)\end{array}$ \\
\hline $69 \mathrm{KV}$ and below & 3 & 5 \\
\hline $69.001 \mathrm{KV}$ through $161 \mathrm{KV}$ & 1.5 & 2.5 \\
\hline $161.001 \mathrm{KV}$ and above & 1 & 1.5 \\
\hline
\end{tabular}

Table 2 similarly gives the current distortion limits. $\mathrm{I}_{\mathrm{SC}}=$ Maximum short circuit current at (PCC) point of common coupling, $\mathrm{I}_{\mathrm{L}}=$ Maximum demand load current (fundamental frequency component) at PCC and $\mathrm{h}=$ harmonic order and TDD is the total root-sumsquare harmonic current distortion, in percent of the maximum demand load current (15 or 30 min demand).

Table 2. Current Distortion Limits

\begin{tabular}{|c|c|c|c|c|c|c|}
\hline \multicolumn{7}{|c|}{ Maximum Harmonics Current Distribution in Percent of $\mathrm{I}_{\mathrm{L}}$} \\
\hline \multicolumn{7}{|c|}{ Individual Harmonic Order (Odd Harmonics } \\
\hline $\mathrm{I}_{\mathrm{SC}} / \mathrm{I}_{\mathrm{L}}$ & $<11$ & $11 \leq \mathrm{h} \leq 17$ & $17 \leq \mathrm{h} \leq 23$ & $23 \leq \mathrm{h} \leq 25$ & $35 \leq \mathrm{h}$ & TDD \\
\hline$<20$ & 4.0 & 2 & 1.5 & 0.6 & 0.3 & 5 \\
\hline $20<50$ & 7.0 & 3.5 & 2.5 & 1 & 0.5 & 8 \\
\hline $50<100$ & 10.0 & 4.5 & 4 & 1.5 & 0.7 & 12 \\
\hline $100<1000$ & 12.0 & 5.5 & 5 & 2 & 1 & 15 \\
\hline$>1000$ & 15.0 & 7 & 6 & 2.5 & 1.4 & 20 \\
\hline
\end{tabular}

\section{Implementation}

Passive harmonic filters are the commonly used and widely implemented for harmonic voltage and current distortion [3, 7]. These can be installed in any industrial power system to act alone or in combination with phase shifting transformers. Passive single tuned filters are considered to be the simplest and effective solution for reducing harmonics distortion as advance techniques like magnetic flux compensation, pulse width modulated static Var harmonic compensators are practically not available for implementation. The most commonly used passive filters are single tuned type connected in shunt with the main distribution system and is tuned to provide low impedance to a particular harmonic frequency thereby diverting the harmonic currents [8]. These filters consist of reactor and capacitor and the quality factor $(\mathrm{Q})$ of the filter determines the sharpness of tuning. Typical value of Q generally ranges from 30-60 which plays a vital role in filter designing. Five (single tuned) passive filters are used and are connected at buses $6,7 \& 8$ having general $\mathrm{R}, \mathrm{L}$ and $\mathrm{C}$ combinations which are tuned according to the harmonic numbers. Filter designing in MiPower Software is done by following method consider the following equation: MVAR of the capacitor is given by:

$$
P\left[\tan \left(\cos ^{-1}\left(p f_{1}\right)\right)-\tan \left(\cos ^{-1}\left(p f_{2}\right)\right)\right]
$$

Where $\mathrm{P}$ is active power of the load, $\mathrm{pf}_{1}$ is actual power factor and $\mathrm{pf}_{2}$ is the desired power factor that helps to determine the filter size. The quality factor is taken as 40 and details of MVAR of the filter are given to get the desired value of R (ohms), L (Henry) and $\mathrm{C}$ (Farad) for the suppression of $5^{\text {th }}$ and $7^{\text {th }}$ harmonic distortion. 


\section{Simulation \& Results}

The test system is simulated and the results depicts that the harmonic distortion is found to be exceedingly high in the $6^{\text {th }}, 7^{\text {th }}$ and $8^{\text {th }}$ bus. Further it is also obtained that the $5^{\text {th }}$ order harmonic is dominant at the $6^{\text {th }}$ bus and $7^{\text {th }}$ and $8^{\text {th }}$ bus have both $5^{\text {th }}$ as well as $7^{\text {th }}$ order harmonics as dominant parameters. The simulation diagram with filters connected at the desired buses is given in Figure 3. The filter parameters used to limit the harmonic distortion are given in the table below:

\section{Table 3. Passive Filter Parameters for $5^{\text {th }}$ and $7^{\text {th }}$ Harmonics Mitigation}

\begin{tabular}{|c|c|c|c|c|}
\hline Bus No & Harmonic order & Resistance $(\Omega)$ & Inductance $(\mathrm{H})$ & Capacitance $(\mathrm{F})$ \\
\hline 6 & $5^{\text {th }}$ & 0.033383 & 0.000850 & 0.000477 \\
\hline 7 & $5^{\text {th }}$ & 0.025037 & 0.000638 & 0.000636 \\
\cline { 2 - 5 } & $7^{\text {th }}$ & 0.009707 & 0.000177 & 0.001171 \\
\hline \multirow{2}{*}{8} & $5^{\text {th }}$ & 0.000668 & 0.000851 & 0.000477 \\
\cline { 2 - 5 } & $7^{\text {th }}$ & 0.009278 & 0.000169 & 0.001225 \\
\hline
\end{tabular}

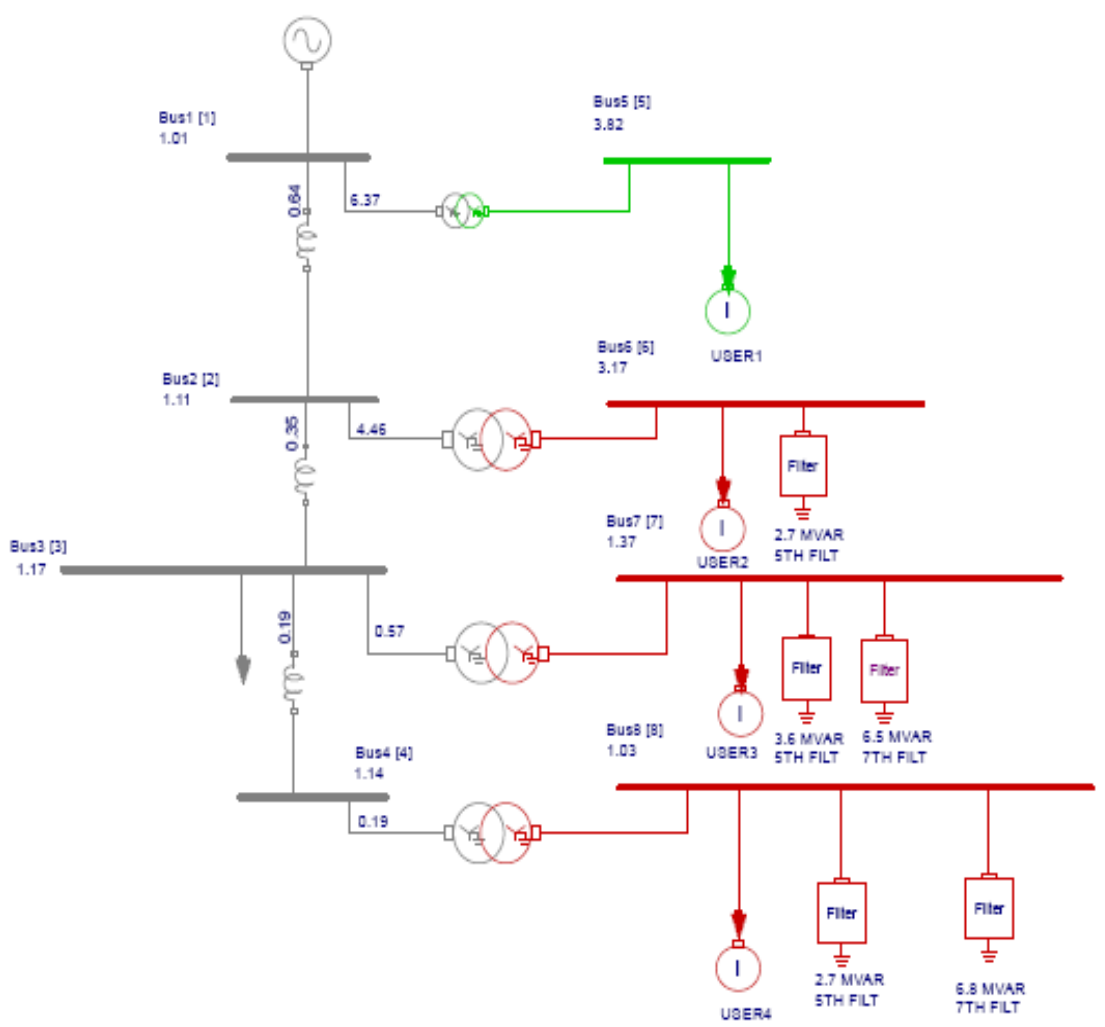

Figure 3. Simulation Diagram of the Test System

The graphs indicating the overall harmonic reduction considering the dominant $5^{\text {th }}$ and $7^{\text {th }}$ harmonic component at the concerned buses are given in figure 4-13. Case A depicts the results without connecting the filters and case $\mathrm{B}$ gives the results with filters connected at Bus 6, 7 and 8 that clearly indicates the improved system performance. 


\section{CASE A: (Without Filters)}

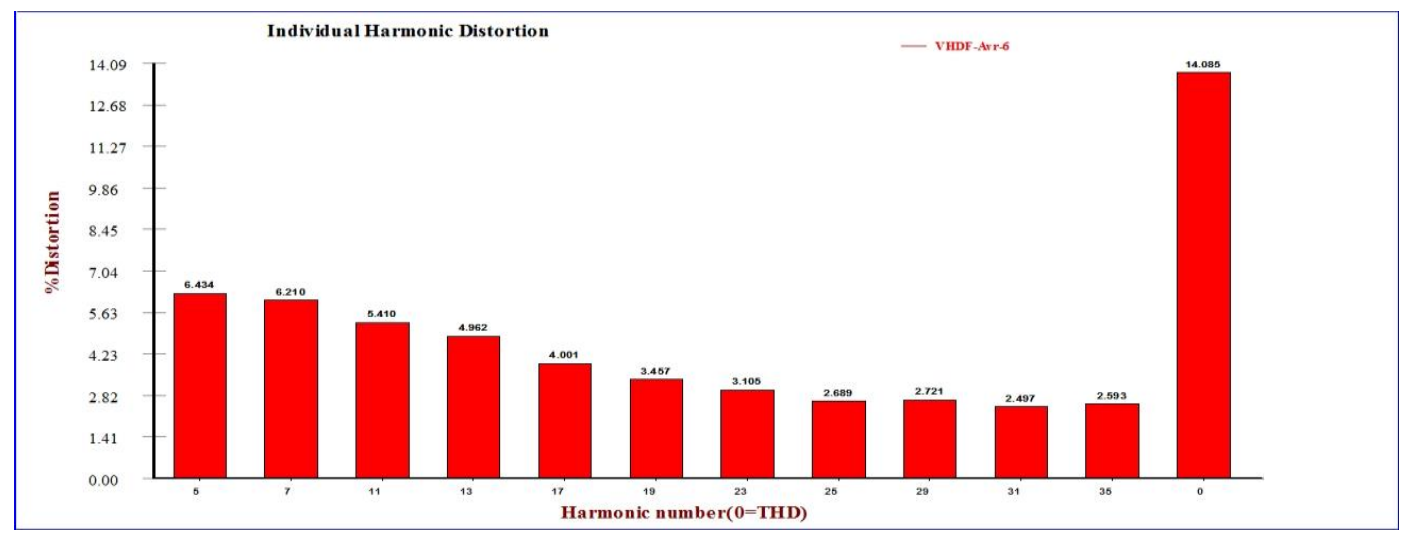

Figure 4. Individual Harmonic Distortion at Bus 6

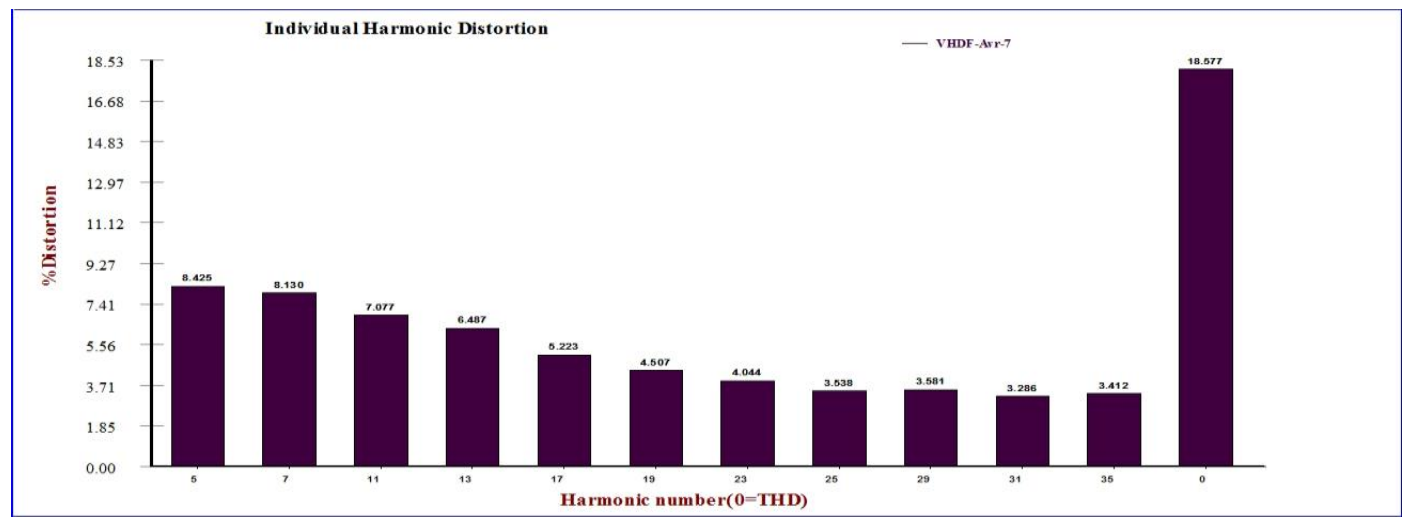

Figure 5. Individual Harmonic Distortion at Bus 7

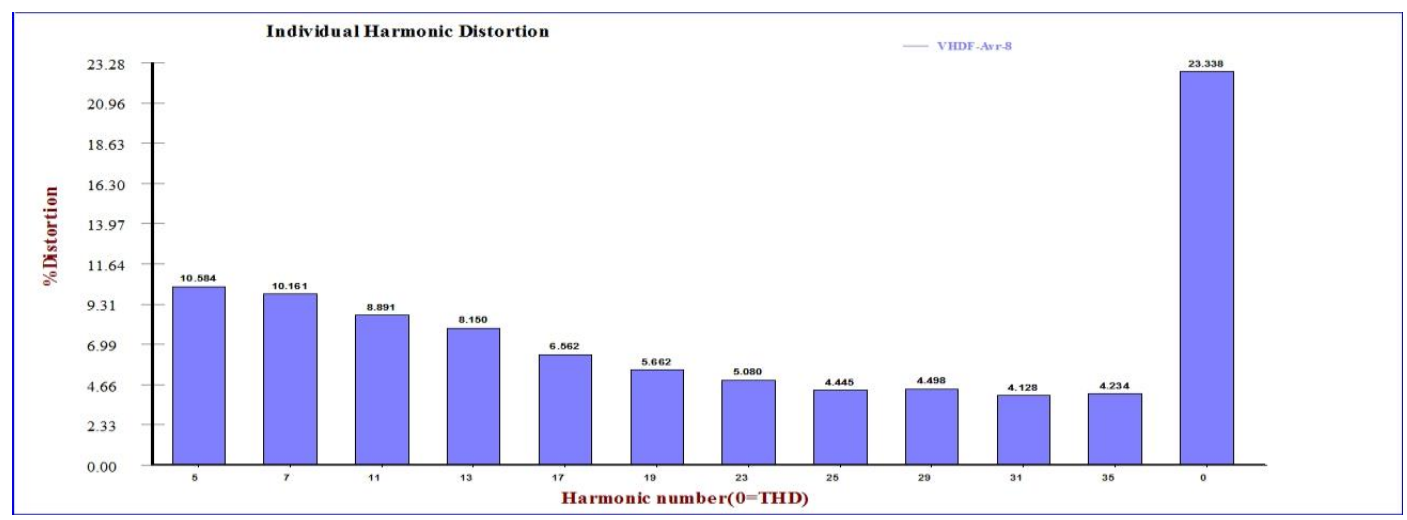

Figure 6. Individual Harmonic Distortion at Bus 8 


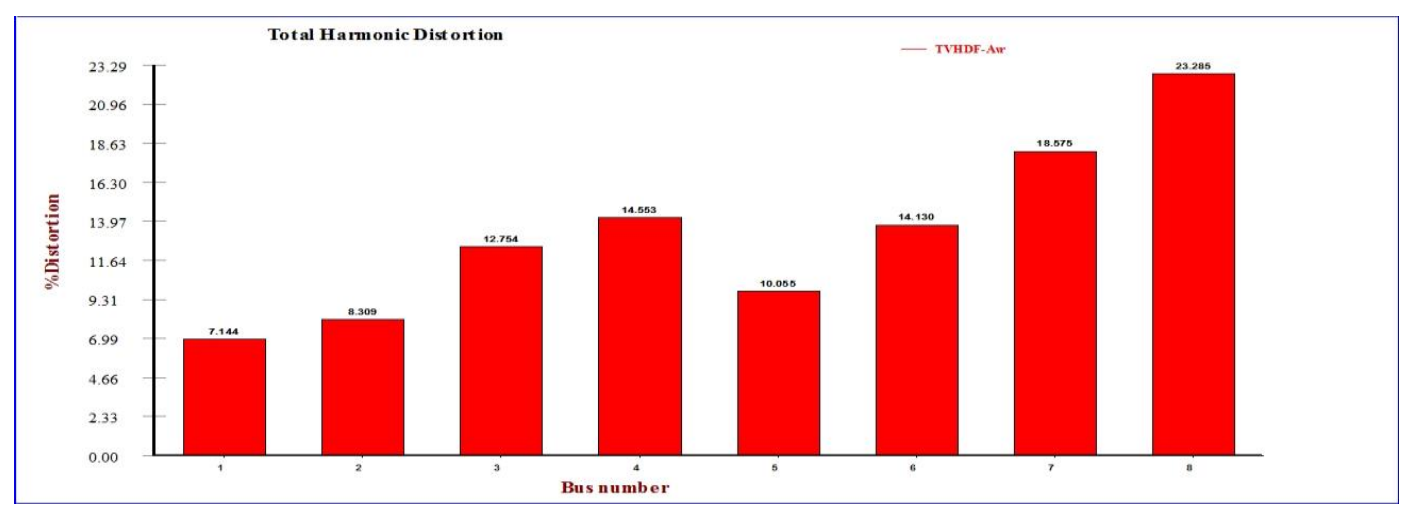

Figure 7. Total Voltage Harmonic Distortion at all buses

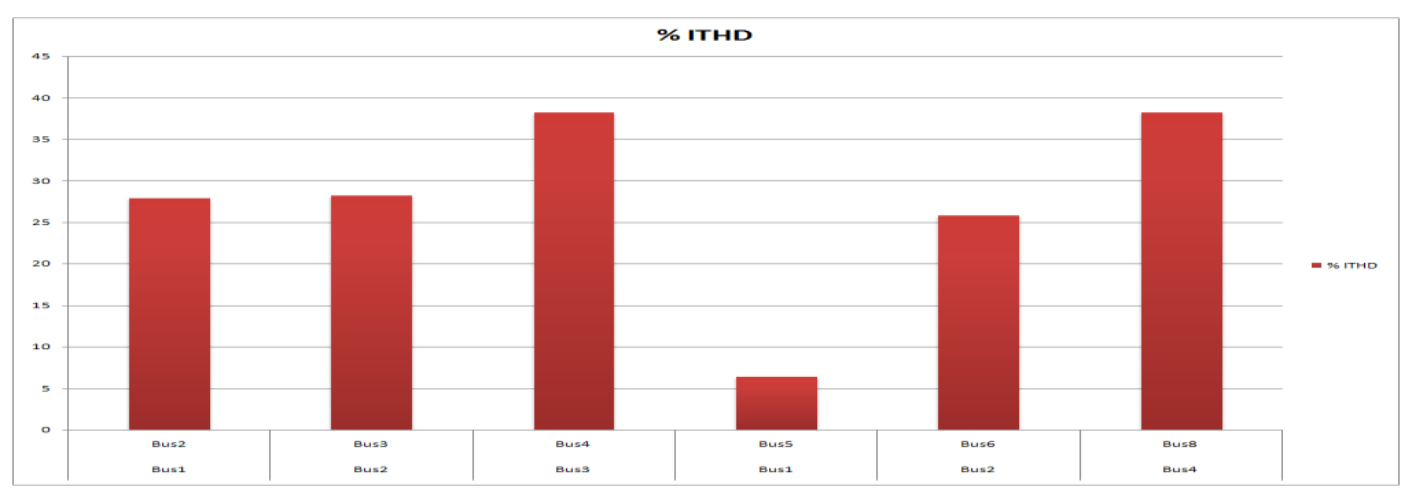

Figure 8. Total Current Harmonic Distortion at all Buses

CASE B: (With Filters)

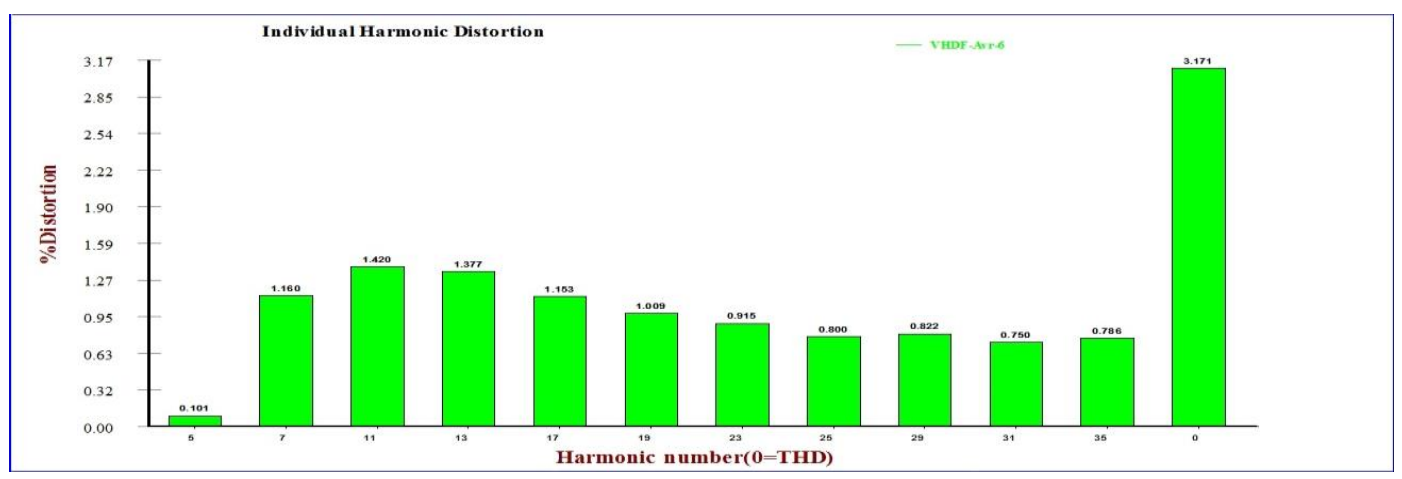

Figure 9. Individual Harmonic Distortion at Bus 6

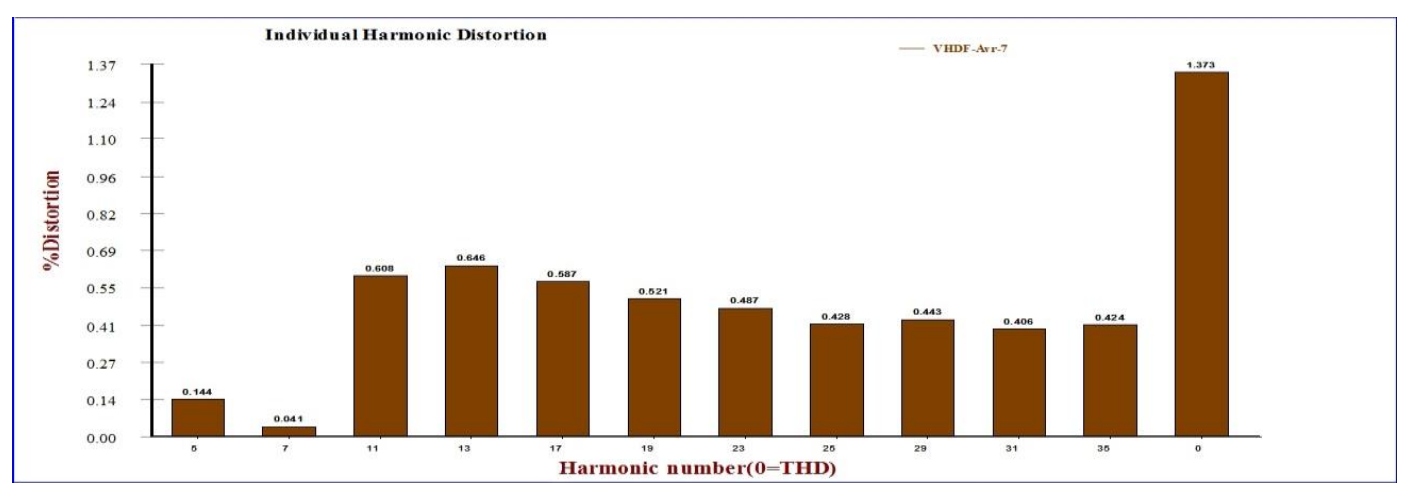

Figure 10. Individual Harmonic Distortion at Bus 7 


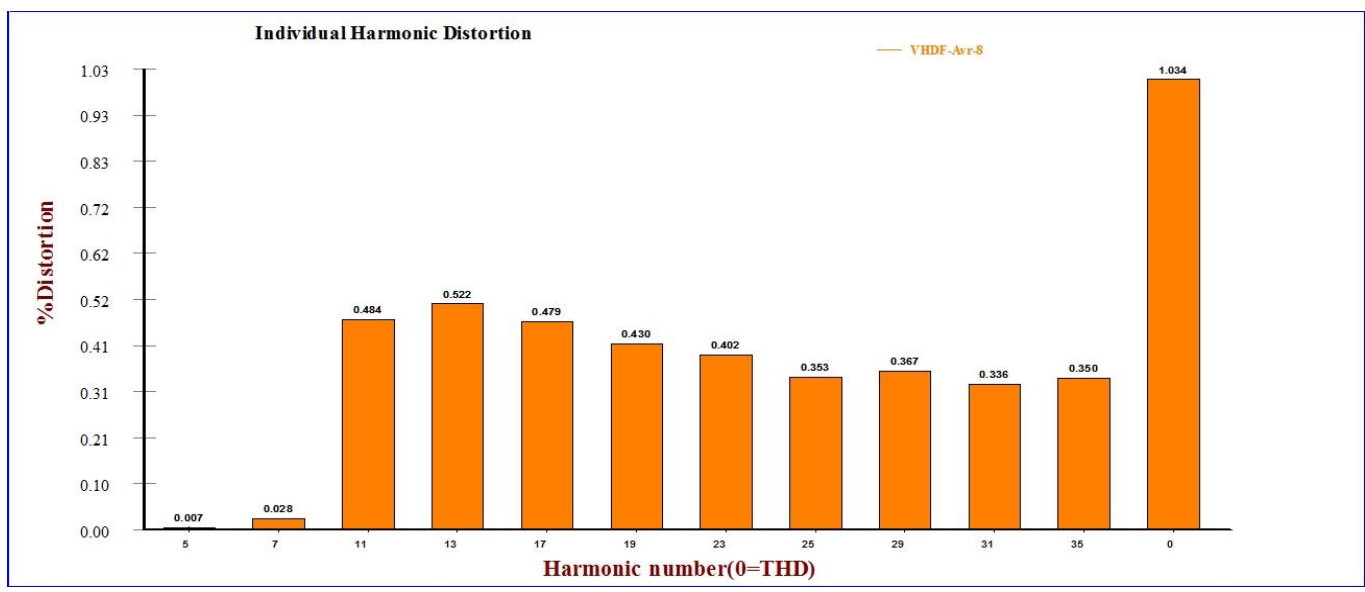

Figure 11. Individual Harmonic Distortion at Bus 8

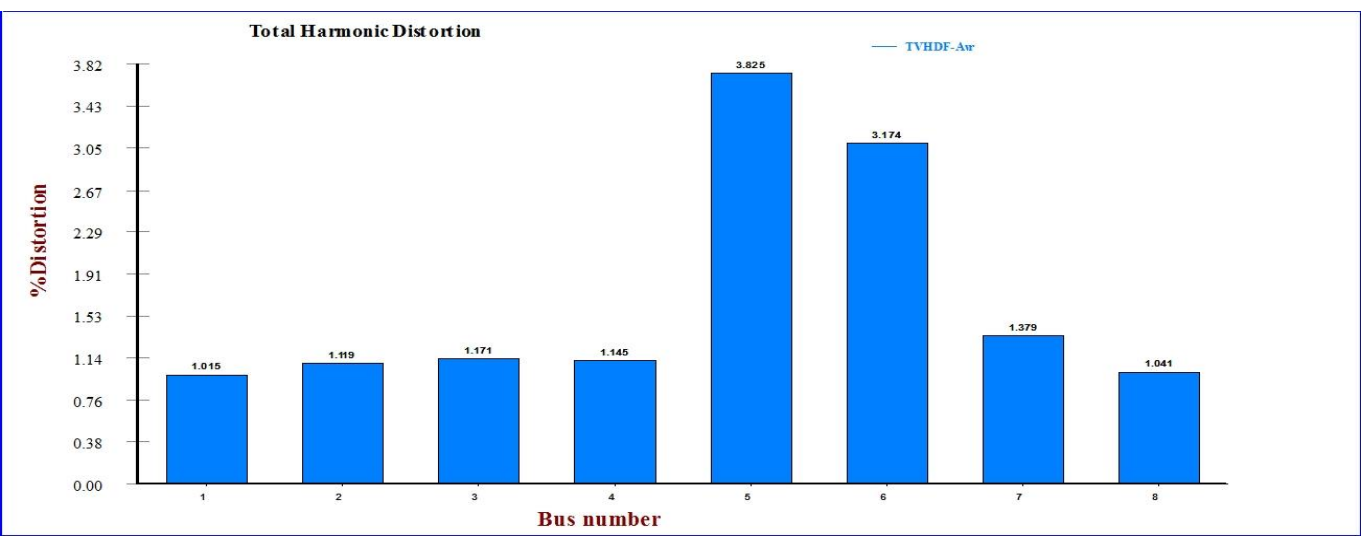

Figure 12. Total Voltage Harmonic Distortion at all Buses with Filters

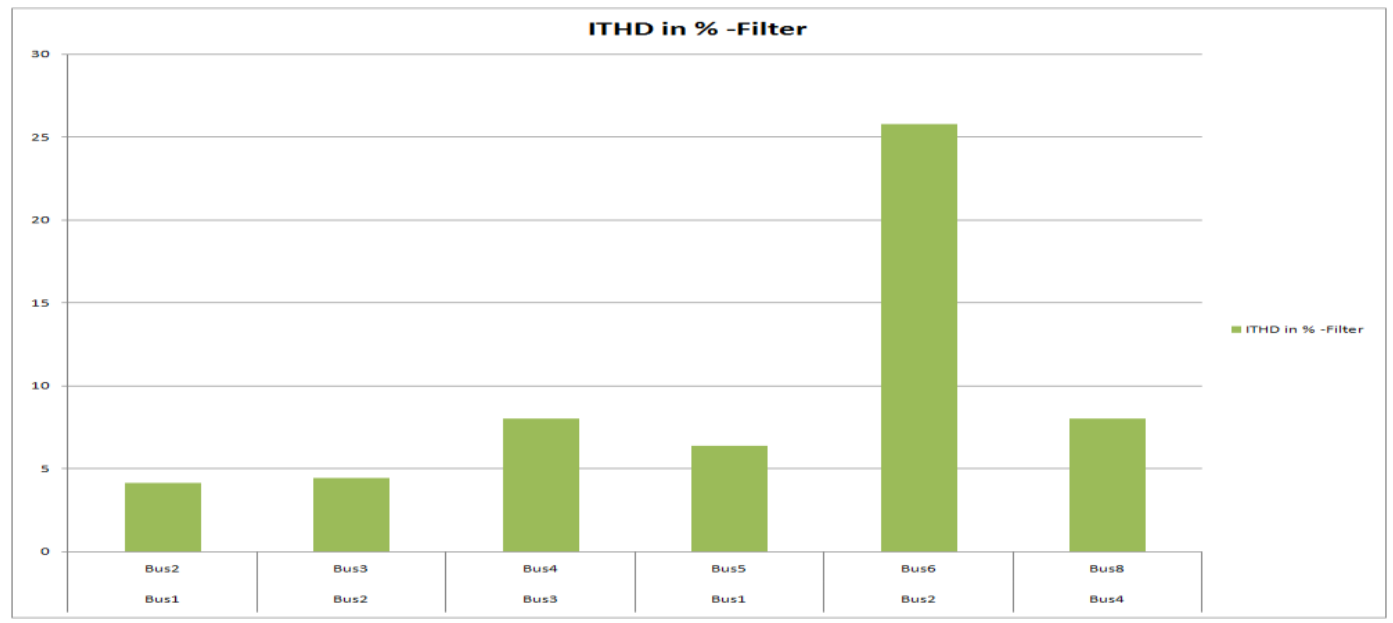

Figure 13. Total Current Harmonic Distortion at all Buses with Filters

\section{Case A (Without filter):}

Table 4 gives the detail simulation result for individual voltage harmonic distortion considering different harmonic order without filters. 
Table 4. Individual Voltage Harmonic Distortion

\begin{tabular}{|c|c|c|c|c|c|c|}
\hline NAME & \%HDF-T & \%HDF-5 & \%HDF-7 & \%HDF-11 & \%HDF-13 & \%HDF-17 \\
\hline Bus1 & 7.1288 & 3.257 & 3.1373 & 2.7313 & 2.5141 & 2.02 \\
\hline Bus2 & 8.2652 & 3.7763 & 3.6374 & 3.1667 & 2.9149 & 2.342 \\
\hline Bus3 & 12.7216 & 5.8115 & 5.5979 & 4.8761 & 4.4866 & 3.6048 \\
\hline Bus4 & 14.539 & 6.6413 & 6.3968 & 5.5735 & 5.1281 & 4.1202 \\
\hline Bus5 & 10.0173 & 4.5773 & 4.4078 & 3.8372 & 3.5322 & 2.8386 \\
\hline Bus6 & 14.0851 & 6.4386 & 6.2023 & 5.3878 & 4.9676 & 3.9911 \\
\hline Bus7 & 18.535 & 8.4672 & 8.1569 & 7.1053 & 6.5357 & 5.2508 \\
\hline Bus8 & 23.2853 & 10.6345 & 10.2414 & 8.93 & 8.2152 & 6.6011 \\
\hline
\end{tabular}

Table 5 gives the detail simulation result for total voltage harmonic distortion in all the three phases of ac system without filters connected to the test system. HDF is the measure of harmonic distortion factor whose average value is computed for each bus.

Table 5. Total Voltage Harmonic Distortion

\begin{tabular}{|c|c|c|c|c|}
\hline NAME & \%HDF-A & \%HDF-B & \%HDF-C & \%HDF-Average \\
\hline Bus1 & 7.1288 & 7.1288 & 7.1288 & 7.1288 \\
\hline Bus2 & 8.2652 & 8.2652 & 8.2652 & 8.2652 \\
\hline Bus3 & 12.7216 & 12.7216 & 12.7216 & 12.7216 \\
\hline Bus4 & 14.539 & 14.539 & 14.539 & 14.539 \\
\hline Bus5 & 10.0173 & 10.0173 & 10.0173 & 10.0173 \\
\hline Bus6 & 14.0851 & 14.0851 & 14.0851 & 14.0851 \\
\hline Bus7 & 18.535 & 18.535 & 18.535 & 18.535 \\
\hline Bus8 & 23.2853 & 23.2853 & 23.2853 & 23.2853 \\
\hline
\end{tabular}

Table 6 gives the detail simulation result for total current harmonic distortion where ITHD gives the current distortion values in $\%$.

Table 6. Total Current Harmonic Distortion

\begin{tabular}{|c|c|c|c|c|c|}
\hline $\begin{array}{c}\text { NAM } \\
\mathrm{E}\end{array}$ & $\begin{array}{c}\text { NAM } \\
\mathrm{E}\end{array}$ & $\begin{array}{c}\text { RMS- } \\
\text { HARMONIC(A) }\end{array}$ & $\begin{array}{c}\text { FUNDAMENTAL } \\
(\mathrm{A})\end{array}$ & $\begin{array}{c}\text { RMS- } \\
\text { TOTAL(A) }\end{array}$ & $\begin{array}{c}\text { I-THD } \\
(\%)\end{array}$ \\
\hline Bus1 & Bus2 & 120.955838 & 434.244866 & 450.775907 & 27.854 \\
\hline Bus2 & Bus3 & 93.94209 & 333.310477 & 346.296103 & 28.185 \\
\hline Bus3 & Bus4 & 40.281306 & 105.430727 & 112.863731 & 38.206 \\
\hline Bus1 & Bus5 & 6.673873 & 104.777882 & 104.990215 & 6.37 \\
\hline Bus2 & Bus6 & 27.013755 & 104.780031 & 108.206275 & 25.781 \\
\hline Bus4 & Bus8 & 40.281253 & 105.42634 & 112.859614 & 38.208 \\
\hline
\end{tabular}




\section{Case B (With filters):}

Table 7. Individual Voltage Harmonic Distortion

\begin{tabular}{|c|c|c|c|c|c|c|}
\hline NAME & \%HDF-T & \%HDF-5 & \%HDF-7 & \%HDF-11 & \%HDF-13 & $\%$ HDF-17 \\
\hline Bus1 & 1.0138 & 0.1101 & 0.2643 & 0.4299 & 0.4255 & 0.3653 \\
\hline Bus2 & 1.1149 & 0.1012 & 0.2780 & 0.4726 & 0.4693 & 0.4042 \\
\hline Bus3 & 1.1704 & 0.0812 & 0.1661 & 0.4847 & 0.4956 & 0.4378 \\
\hline Bus4 & 1.1421 & 0.0667 & 0.1349 & 0.4682 & 0.4828 & 0.4297 \\
\hline Bus5 & 3.8160 & 1.4183 & 1.5294 & 1.5317 & 1.4398 & 1.1810 \\
\hline Bus6 & 3.1709 & 0.0925 & 1.1109 & 1.1324 & 1.3187 & 1.1076 \\
\hline Bus7 & 1.3732 & 0.1257 & 0.0352 & 0.5423 & 0.5721 & 0.5215 \\
\hline Bus8 & 1.0338 & 0.0053 & 0.0227 & 0.3990 & 0.2491 & 0.3955 \\
\hline
\end{tabular}

Table 8 gives the detail simulation result for total voltage harmonic distortion in all the three phases of ac system with filters connected at bus 6,7 and 8 in the test system. The results show an overall reduction in harmonic voltage distortion level by proper sizing and parameter selection of the single tuned passive filters.

Table 8. Total Voltage Harmonic Distortion

\begin{tabular}{|c|c|c|c|c|}
\hline NAME & \%HDF-A & \%HDF-B & \%HDF-C & \%HDF-Average \\
\hline Bus1 & 1.0138 & 1.0138 & 1.0138 & 1.0138 \\
\hline Bus2 & 1.1149 & 1.1149 & 1.1149 & 1.1149 \\
\hline Bus3 & 1.1704 & 1.1704 & 1.1704 & 1.1704 \\
\hline Bus4 & 1.4121 & 1.4121 & 1.4121 & 1.4121 \\
\hline Bus5 & 3.8160 & 3.8160 & 3.8160 & 3.8160 \\
\hline Bus6 & 3.1709 & 3.1709 & 3.1709 & 3.1709 \\
\hline Bus7 & 1.3732 & 1.3732 & 1.3732 & 1.3732 \\
\hline Bus8 & 1.0338 & 1.0338 & 1.0338 & 1.0338 \\
\hline
\end{tabular}

Table 9 gives the detail simulation result for total current harmonic distortion and it is evident from the values of I-THD the inclusion of filters have reduced the overall current distortion is the test distribution system.

Table 9. Total Current Harmonic Distortion

\begin{tabular}{|c|c|c|c|c|c|}
\hline $\begin{array}{c}\text { NAM } \\
\text { E }\end{array}$ & $\begin{array}{c}\text { NAM } \\
\mathrm{E}\end{array}$ & $\begin{array}{c}\text { RMS- } \\
\text { HARMONIC(A) }\end{array}$ & $\begin{array}{c}\text { FUNDAMENTAL } \\
(\mathrm{A})\end{array}$ & $\begin{array}{c}\text { RMS- } \\
\text { TOTAL(A) }\end{array}$ & $\begin{array}{c}\text { I-THD } \\
(\%)\end{array}$ \\
\hline Bus1 & Bus2 & 6.968 & 1094.45 & 1094.4737 & 0.637 \\
\hline Bus2 & Bus3 & 3.337 & 944.61 & 944.616 & 0.353 \\
\hline Bus3 & Bus4 & 0.939 & 489.71 & 489.717 & 0192 \\
\hline Bus1 & Bus5 & 6.673 & 104.77 & 104.99 & 6.369 \\
\hline Bus2 & Bus6 & 6.919 & 155.073 & 155.227 & 4.462 \\
\hline Bus4 & Bus8 & 0.939 & 489.67 & 489.676 & 0.192 \\
\hline
\end{tabular}




\section{Conclusion}

This paper provides a detailed approach to design single tuned passive filters to mitigate the adverse effect of harmonics. The harmonic level has a great effect on the performance of system components and this paper presents the proper selection of single tuned passive filter parameters ( $\mathrm{R}, \mathrm{L}$ and $\mathrm{C}$ ) and its design to improve system performance by suppressing the dominant $5^{\text {th }}$ and $7^{\text {th }}$ order harmonics. The simulation results depicts that by using passive filters the voltage distortion at main panels-PCC is reduced from 7.13 to 1.01 and current distortion from 27.85 to 0.64 . The software also helps in selecting the location of passive filters to optimize system performance and also suggest a detailed filter designing based upon the filter performance. So, it can be concluded that the model simulated and considered in this study is suitable for performing harmonic analysis and the results obtained meet the recommended IEEE 519 harmonic standards.

\section{Appendix}

\section{Bus Data:}

Bus 1-4 13.8kV, Bus $50.48 \mathrm{kV}$ Bus 6-8 $4.16 \mathrm{kV}$. Minimum and maximum voltages at all buses are 0.95 and 1.05 p.u

\section{Series Reactor Data:}

All the reactors are rated at 10MVA

Reactor bus $1-2 \mathrm{X}=0.00476$

Reactor bus $2-3 \mathrm{X}=0.0238$

Reactor bus 3-4 X=0.02286

\section{Generator Data:}

10 MVA, 20 MW, 1 p.u., $X_{d}=0.02857$

\section{References}

[1] S. D. Upadhye and Y. R. Atre, "Determination of the Design Parameters of Passive Harmonic Filters using Non-linear Optimization", Industrial and commercial power system technical conference, 1998, pp 155-164.

[2] Clyde Gilker, Rory V. Dwyer, Roger C. Dugan, "A Program for Analysis of Power System Harmonics”, IEEE Computer Applications in Power, (1989).

[3] M. E. Habrouk, M. K. Darwish and P. Mehta, "Active Power Filter; A review”, IEE Proc. Electr. Power Appl., Vol. 147, no. 5, (2000) September, pp. 403-413.

[4] Y.-S. Cho and H. Cha, "Single-tuned Passive Harmonic Filter Design Considering Variances of Tuning and Quality Factor", Journal of International Council on Electrical Engineering, vol. 1, no. 1, (2011), pp. 7-13.

[5] IEEE Std. 519-1992, "IEEE Recommended Practices and Requirements for Harmonic Control in Electrical Power Systems", (1992), pp. 77-80.

[6] F. Z. Peng, H. Akagi and A. Nabae, "A New Approach to Harmonic Compensation in Power System a Combined System of Shunt Passive and Series Active Filter", IEEE Trans. On Industry Applications, vol. 27, no. 6, (1990), pp. 983-990.

[7] H. Fujita and H. Akagi, "A Practical Approach to Harmonic Compensation in Power System Series Connection of Passive and Active Filter", IEEE Trans. On Industry Applications, vol. 27, no. 6, (1991), pp. 1020-1025.

[8] Z. Ahmed Memon, M. Uquaili and M. Ali Unar, "Harmonics Mitigation of Industrial Power System Using Passive Filters", Mehran University Research Journal of Engineering \& Technology, vol. 31, no. 2, (2012) April.

[9] R. C. Dugan, "Electrical Power Systems Quality", Second Edition, McGraw-Hill, (2002), pp. 264-273. 


\section{Authors}

Mandeerp Singh, Assistant Professor in the Department of Electrical, Electronics and Communication Engineering, ITM University, Gurgaon, (Haryana), India. He has received his M.Tech and B.Tech. from Sant Longowal Institute of Engg. \& Tech., Longowal, Sangrur (Punjab) in the year of 2008 and 2006 respectively. His main research interests are in Control systems, Power system optimization techniques and its engineering application.

Sheila Mahapatra received her B.Tech degree in Electrical Engineering from Utkal University, Orissa in 2002. She received her Master's degree in Power System \& Automation from GITAM, Andhra University, Vizag in 2008. Presently she is working towards $\mathrm{PhD}$ in the Department of Electrical \& Electronics Engineering, ITM University, Gurgaon, Haryana. She is a lifetime member of ISTE and has teaching experience of over 9years. 